\title{
ORGANOCHLORINE PESTICIDE RESIDUES IN CHEESES FROM LEÓN, SPAIN
}

\author{
ALBERTO SUÁREZ, M. TERESA TERÁN, JUAN J. GARCÍA, \\ MATILDE SIERRA*, NÉLIDA FERNÁNDEZ and M. JOSÉ DIEZ \\ Department of Physiology, Pharmacology and Toxicology, Veterinary Faculty, \\ University of León, Campus de Vegazana, s/n. 24071 León, Spain
}

(Received 30 May 1997; Revised 9 September 1997)

The purpose of this paper was to know the residual levels of 9 organochlorine insecticides (lindane, heptachlor epoxide, aldrin, endrin, dieldrin, o,p'-TDE, p,p'-TDE, p,p'-DDE and p,p'DDT) in cheese samples collected in León, in the north-west of Spain, in 1993 and 1994. The highest individual concentration detected was, in both years, for DDT: $0.9048 \mathrm{ppm}$ (brand no. 6) in 1993 and $0.8581 \mathrm{ppm}$ (brand no. 5) in 1994. The organochlorine pesticide mean load ranged from $0.0197 \mathrm{ppm}$ to $0.3114 \mathrm{ppm}$ in 1993 , and from $0.0416 \mathrm{ppm}$ to $0.3000 \mathrm{ppm}$ in 1994 . The most frequently detected pesticides were heptachlor epoxide $(77.1 \%)$ in 1993 and lindane $(62.5 \%)$ in 1994. None of the samples analyzed exceeded the maximum levels allowed by the present legislation.

Keywords: Organochlorine pesticides; residues; cheese

\section{INTRODUCTION}

As a result of a widespread use in the past, some chlorinated hydrocarbon pesticides were distributed worldwide as environmental pollutants. At present, the use of organochlorine pesticides is banned or very restricted in the developed countries due to their toxicity and high capacity of accumulation in living organisms. Residual levels of organochlorine pesticides are still found in a considerable portion of biological samples [1-3], mainly due to three factors: high persistence, extensive use in many developing countries, and restricted use in many developed countries.

\footnotetext{
${ }^{*}$ Corresponding author.
} 
The EU legislation [4] allows the use of lindane and, severely restricted, endrin and aldrin. Nevertheless, each member country in EU can have additional rules, and thus in Spain only lindane can be used without restrictions for applications on some crops, in timber preservation, for individual treatment of damaged trees and as ectoparasiticide in domestic animals. On the other hand, the DIRECCIÓN General de Salud Pública of the Ministerio de Sanidad $y$ Consumo allows the occasional use of any of these compounds if resistance to other insecticides usually used appears [5].

Milk (cow's milk, principally) is one of the most important media where organochlorine residue levels are monitored. On the other hand, milk and its derivative products have a special place in human diet and it is important to know both if organochlorine pesticide residues are present in this type of samples and if the detected residue levels are below the maximum levels allowed by the legislation established by the EU [6] and by the FAO/WHO [7].

\section{MATERIAL AND METHODS}

A total of ninety-two samples of cheese were obtained from different supermarkets in León, in the North-west of Spain (see Figure 1). These samples belonged to six different brands of cheese (numbered 1 to 6) and 16 samples were collected for each one of them, except for number 4 in which case the last sampling was not carried out due to distribution problems. The brands numbered 1,2 , and 3 were elaborated in the north of the province, in a mountainous area with few culture lands. The other three brands (numbered 4, 5 , and 6) were elaborated in the southern area of the province, where culture

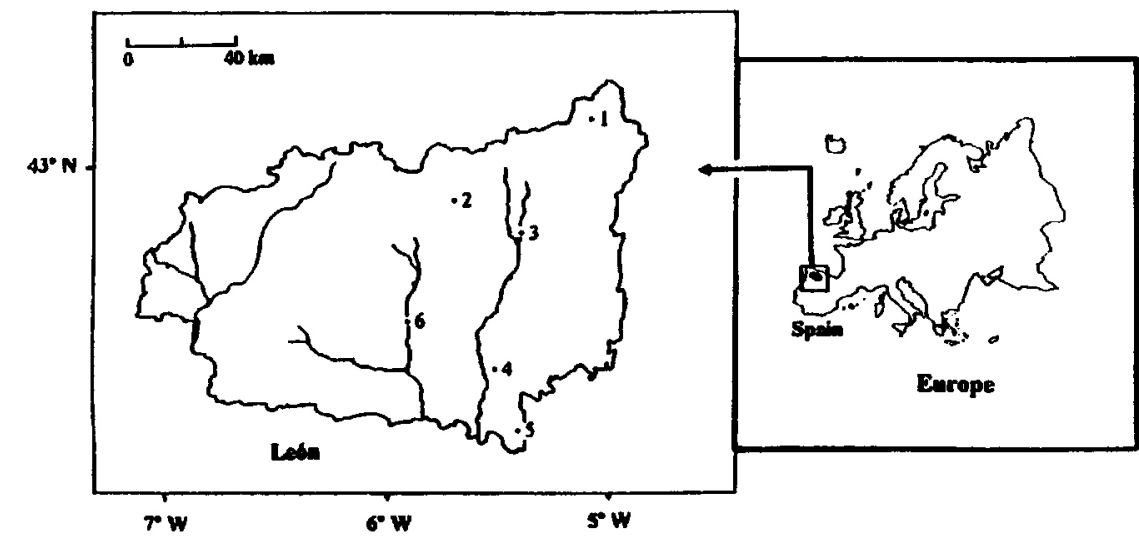

FIGURE 1 Map of León showing the sampling locations 1, 2, 3, 4, 5 and 6, corresponding to the manufacture areas. lands are numerous. All the cheeses utilized for this study were elaborated with milk mainly collected in the influence area of the production place (see Figure 1). Number 1 and 6 were made with cow milk; number 3 with cow and sheep milk and number 2,4 , and 5 with cow, sheep and goat milk. The proportion of the several types of milk were not shown in the cheese labels and so, only the percentage of fat for any kind of cheese was taken into account owing to the fact that organochlorine insecticides are accumulated in fat. In this way, the number 1 had the highest content, 31\%; the numbers 2 , 3,4 , and 5 had the same percentage, $25 \%$, and a $22 \%$ corresponded to the number 6.

Sampling was made in four different times (July and October of 1993 and in January and April of 1994) with intervals of three months, in order to detect possible seasonal variations in contamination. All samples were stored at $-20^{\circ} \mathrm{C}$ until they were analysed.

Organochlorine residues were extracted from cheese samples according to the method proposed in 1990 by the AOAC [8] and $25 \mathrm{~g}$ of each sample were used. Clean-up of the extracts was also carried out by using the AOAC method and all the reagents were suitable for pesticide residue analysis and subjected to general purity tests.

Identification and quantification of residues were made by gas chromatography, with electron capture detection. A standard solution of nine organochlorine pesticides (lindane, heptachlor epoxide, aldrin, endrin, dieldrin, o,p'-TDE, p,p'-TDE, p,p'-DDE and p,p'-DDT) was used to identify and quantify the residue levels. The pesticides were purchased from Dr. Ehrenstorfer GmbH, Scharlau (Augsburg, Germany). These insecticides are contained' in the standard hexane solution at the following concentrations (in ppm): 0.090 (lindane), 0.062 (heptachlor epoxide), 0.060 (aldrin), 0.081 (endrin), 0.048 (dieldrin), 0.075 (o,p'-TDE), 0.072 (p,p'-TDE), 0.095 (p,p'-DDE) and 0.165 (p,p'-DDT).

The peaks were identified by comparison of retention times with those of the standard and tolerance allowed was $\pm 5 \%$ of retention times. The detection limit was established in $0.0005 \mu \mathrm{g} / \mathrm{mL}$ for dieldrin and o,p'-TDE; $0.001 \mu \mathrm{g} / \mathrm{mL}$ for lindane, heptachlor epoxide, aldrin, endrin and p, '-TDE and $0.005 \mu \mathrm{g} / \mathrm{mL}$ for p,p'-DDE and p,p'-DDT. Residue concentrations in samples were calculated by comparing the peak areas in the sample with those showed by the mixed standard solution.

Recoveries of organochlorine pesticides from fortified samples by this method were: $80.0 \%$ for dieldrin, $81.3 \%$ for aldrin, $83.5 \%$ for endrin, $85 \%$ for o,p'-TDE, $86.3 \%$ for DDT, $89.1 \%$ for p,p'-TDE, $90.2 \%$ for heptachlor epoxide, and $100 \%$ for $\mathrm{p}, \mathrm{p}$-DDE and lindane. Residue levels detected were corrected according to their recoveries. 
A Hewlett-Packard gas chromatograph equipped with a ${ }^{63} \mathrm{Ni}$ electron capture detector was used. The carrier gas was argon-methane $5 \%(\mathrm{v} / \mathrm{v})$ at a flow rate of $25 \mathrm{~mL} / \mathrm{min}$ and sample volume injected was $3 \mu \mathrm{L}$. Two columns were utilized:

Column a) Glass, $185 \mathrm{~cm}$ long and $0.4 \mathrm{~cm}$ internal diameter containing a $10 \%$ coating of DC-200 on 80-100 mesh Chromosorb WHP [8]. A second glass column b) packed with $1.95 \%$ QF-1/1.5\% OV-17 on 100/120 mesh Chromosorb W(AW/OMCS) was used to confirm the identity of the organochlorine residues when necessary. The operating temperatures were: inlet, $240^{\circ} \mathrm{C}$ (column a) and $220^{\circ} \mathrm{C}$ (column b); detector, $300^{\circ} \mathrm{C}$; column (a) $220^{\circ} \mathrm{C}$ (21 minutes) and $230^{\circ} \mathrm{C}$ (10 minutes); column (b) $180^{\circ} \mathrm{C}\left(15\right.$ minutes) and $190^{\circ} \mathrm{C}(20$ minutes $)$, with an intermediate temperature increase, in both cases, of $10^{\circ} \mathrm{C} / \mathrm{min}$.

The influence of the locations where cheeses were produced in residual levels detected for each pesticide and in the total residues was analysed for statistical significance by using the analysis of variance (ANOVA), when possible. In the same way the influence of sampling period was analysed. When the results were significant, Duncan test was used to evaluate differences between data sets and a $\mathrm{P} \leq 0.05$ was taken as the level of significance for all analyses. The STATGRAPHICS program [9] was employed to carry out the statistical tests.

\section{RESULTS AND DISCUSSION}

The mean concentrations (in $\mathrm{ppm} / \mathrm{fat}$ basis), ranges and incidence percentages of organochlorine residues obtained in the 92 cheese samples analyzed are shown in Tables I to VI. These tables have been elaborated taking into account the year (1993 and 1994, when samples were collected).

In three samples no insecticide was detected; one of them belonged to the brand no. 1 and the other two to the brand no. 6. Heptachlor epoxide and lindane were found in 58 and 57 cheese samples, respectively, and they were the most frequently detected pesticides. p,p'-DDE was present in 30 samples, being the organochlorine compound belonging to the DDT group most frequently seen

Taking into account the brands and the year of sampling, heptachlor epoxide was the most detected pesticide in the brands 2, 3, 4, 5 (in 1993) and 6 (in 1993). Lindane was also detected at the highest percentage in the brands 1 (in 1993), 3 (in 1993, together with heptachlor epoxide), and 4, 5, and 6 (in 1994). In some samples the presence of aldrin is detected, is spite of this insecticide is enzymatically oxidized to dieldrin. Other authors $[1,3]$ have also detected aldrin in milk samples and this fact is reported in the Monograph on
TABLE I Mean, incidence (\%) and range (ppm) of organochlorine pesticides in cheese brand no. 1

\begin{tabular}{|c|c|c|c|}
\hline & 1993 & 1994 & $\begin{array}{c}\text { Total } \\
(1993,1994)\end{array}$ \\
\hline Lindane & $\begin{array}{l}0.0557(75 \%) \\
0.0028-0.0899\end{array}$ & $\begin{array}{l}0.0533(25 \%) \\
0.0460-0.0607\end{array}$ & $\begin{array}{l}0.0551(50 \%) \\
0.0028-0.0899\end{array}$ \\
\hline $\begin{array}{l}\text { Heptachlor } \\
\text { epoxide }\end{array}$ & $\begin{array}{l}0.0378(25 \%) \\
0.0129-0.0627\end{array}$ & $\begin{array}{c}0.0045(12.5 \%) \\
-\end{array}$ & $\begin{array}{l}0.0267(18.75 \%) \\
0.0045-0.0627\end{array}$ \\
\hline DDE & - & $\begin{array}{l}0.1825(37.5 \%) \\
0.0913-0.2581\end{array}$ & $\begin{array}{l}0.1825(18.75 \%) \\
0.0913-0.2581\end{array}$ \\
\hline o,p'-TDE & - & $\begin{array}{l}0.0127(62.5 \%) \\
0.0091-0.0157\end{array}$ & $\begin{array}{l}0.0127(31.25 \%) \\
0.0091-0.0157\end{array}$ \\
\hline $\mathrm{p}, \mathrm{p}^{\prime}-\mathrm{TDE}$ & - & $\begin{array}{c}0.0059(12.5 \%) \\
-\end{array}$ & $\begin{array}{c}0.0059(6.25 \%) \\
-\end{array}$ \\
\hline Aldrin & $\begin{array}{l}0.0141(37.5 \%) \\
0.0073-0.0205\end{array}$ & $\begin{array}{c}0.0030(12.5 \%) \\
-\end{array}$ & $\begin{array}{l}0.0113(25 \%) \\
0.0030-0.0205\end{array}$ \\
\hline Endrin & - & $\begin{array}{c}0.0123(12.5 \%) \\
-\end{array}$ & $\begin{array}{c}0.0123(6.25 \%) \\
-\end{array}$ \\
\hline Mean Load & 0.0565 & 0.0929 & 0.0747 \\
\hline
\end{tabular}

TABLE II Mean, incidence (\%) and range (ppm) of organochlorine pesticides in cheese brand no. 2

\begin{tabular}{llll}
\hline & 1993 & \multicolumn{1}{c}{1994} & \multicolumn{1}{c}{$\begin{array}{c}\text { Total } \\
(1993,1994)\end{array}$} \\
\hline Lindane & $0.0140(50 \%)$ & $0.0292(37.5 \%)$ & $0.0205(43.75 \%)$ \\
Heptachlor & $0.0097-0.0188$ & $0.0017-0.0490$ & $0.0017-0.0490$ \\
epoxide & $0.0132(87.5 \%)$ & $0.0045(37.5 \%)$ & $0.0106(62.5 \%)$ \\
DDE & $0.0021-0.0376$ & $0.0030-0.0052$ & $0.0021-0.0376$ \\
& $0.0166(37.5 \%)$ & $0.0221(37.5 \%)$ & $0.0194(37.5 \%)$ \\
o,p'-TDE & $0.0056-0.0377$ & $0.0184-0.0251$ & $0.0056-0.0377$ \\
& $0.0071(37.5 \%)$ & & $0.0071(18.75 \%)$ \\
p,p'-TDE & $0.0035-0.0112$ & - & $0.0035-0.0112$ \\
& - & $0.0082(37.5 \%)$ & $0.0082(18.75 \%)$ \\
DDT & - & $0.0021-0.0191$ & $0.0021-0.0191$ \\
& $0.0069(12.5 \%)$ & $0.0390(25 \%)$ & $0.0283(18.75 \%)$ \\
Aldrin & - & $0.0079-0.0701$ & $0.0069-0.0701$ \\
& $0.0033(37.5 \%)$ & $0.0044(37.5 \%)$ & $0.0038(37.5 \%)$ \\
Dieldrin & $0.0019-0.0056$ & $0.0011-0.0069$ & $0.0011-0.0069$ \\
& $0.0025(12.5 \%)$ & $0.0039(25 \%)$ & $0.0035(18.75 \%)$ \\
Mean Load & - & $0.0031-0.0047$ & $0.0025-0.0047$ \\
\hline
\end{tabular}


TABLE III Mean, incidence (\%) and range (ppm) of organochlorine pesticides in cheese brand no. 3

\begin{tabular}{lcll}
\hline & 1993 & 1994 & \multicolumn{1}{c}{$\begin{array}{c}\text { Total } \\
(1993,1994)\end{array}$} \\
\hline Lindane & $0.0076(75 \%)$ & $0.0154(37.5 \%)$ & $0.0102(56.25 \%)$ \\
& $0.0017-0.0155$ & $0.0018-0.0273$ & $0.0017-0.0273$ \\
Heptachlor & $0.0120(75 \%)$ & $0.0045(50 \%)$ & $0.0090(62.5 \%)$ \\
epoxide & $0.0022-0.0381$ & $0.0013-0.0069$ & $0.0013-0.0381$ \\
DDE & $0.0064(37.5 \%)$ & $0.0308(50 \%)$ & $0.0203(43.75 \%)$ \\
& $0.0057-0.0075$ & $0.0157-0.0462$ & $0.0057-0.0462$ \\
o,p'-TDE & $0.0029(37.5 \%)$ & $0.0156(12.5 \%)$ & $0.0061(25 \%)$ \\
p,p'-TDE & $0.0009-0.0064$ & - & $0.0009-0.0156$ \\
& - & $0.0113(25 \%)$ & $0.0113(12.5 \%)$ \\
DDT & - & $0.0022-0.0204$ & $0.0022-0.0204$ \\
Dieldrin & - & $0.0812(25 \%)$ & $0.0812(12.5 \%)$ \\
Aldrin & $0.0029(12.5 \%)$ & $0.0052-0.1572$ & $0.0052-0.1572$ \\
& - & $0.0036(50 \%)$ & $0.0034(31.25 \%)$ \\
Endrin & - & $0.0012-0.0056$ & $0.0012-0.0056$ \\
& - & - & $0.0049(6.25 \%)$ \\
Mean Load & 0.0197 & $0.0110(12.5 \%)$ & $0.0110(6.25 \%)$ \\
\hline
\end{tabular}

Residues and Contaminants in Milk and Milk Products, published in 1991 by the International Dairy Federation [10].

DDT and analogs were generally found at low percentages and in brand no. 1 DDT was not detected in any sample. Nevertheless, the highest mean and individual concentrations were determined for pesticides of this group. So in both years, the highest individual concentration was for DDT: $0.9048 \mathrm{ppm}$ (brand no. 6) in 1993 and $0.8581 \mathrm{ppm}$ (brand no. 5) in 1994. In relation to the organochlorine pesticide mean load, it ranged in 1993 from $0.0197 \mathrm{ppm}$ (brand no. 3) to $0.3114 \mathrm{ppm}$ (brand no. 6), and from $0.0416 \mathrm{ppm}$ (brand no. 2) to $0.3000 \mathrm{ppm}$ (brand no. 5) in 1994.

Organochlorine residue levels detected in cheese samples were compared to the maximum residue limit recommended by the Codex Committee FAO/WHO for Pesticide Residues and also to the Maximum Residue Limits for Chlorinated Pesticides proposed by the European Union.

The Maximum Residue Limits for Chlorinated Pesticides proposed by the European Union in cheese are (expressed in $\mathrm{mg} / \mathrm{kg}$ on fat basis) 0.2 for lindane, 0.15 for dieldrin (incl. aldrin), 1 for $\Sigma$ DDT, 0.02 for endrin, and 0.1 for
TABLE IV Mean, incidence (\%) and range (ppm) of organochlorine pesticides in cheese brand no. 4

\begin{tabular}{lccc}
\hline & 1993 & 1994 & $\begin{array}{c}\text { Total } \\
(1993,1994)\end{array}$ \\
\hline Lindane & $0.0050(62.5 \%)$ & $0.0153(100 \%)$ & $0.0096(75 \%)$ \\
& $0.0038-0.0060$ & $0.0113-0.0193$ & $0.0038-0.0193$ \\
Heptachlor & $0.0266(100 \%)$ & $0.0077(100 \%)$ & $0.0203(100 \%)$ \\
epoxide & $0.0019-0.0769$ & $0.0024-0.0172$ & $0.0019-0.0769$ \\
DDE & $0.0180(37.5 \%)$ & $0.0458(25 \%)$ & $0.0249(33.33 \%)$ \\
o,p'-TDE & $0.0076-0.0232$ & - & $0.0076-0.0458$ \\
p,p'-TDE & $0.0111(37.5 \%)$ & $0.0120(75 \%)$ & $0.0115(50 \%)$ \\
& $0.0008-0.0170$ & $0.0041-0.0183$ & $0.0008-0.0183$ \\
DDT & - & $0.0266(25 \%)$ & $0.0266(8.33 \%)$ \\
Aldrin & - & - & - \\
& $0.0058(12.5 \%)$ & $0.1039(25 \%)$ & $0.0548(16.67 \%)$ \\
Dieldrin & - & - & $0.0058-0.1039$ \\
& $0.0036(12.5 \%)$ & - & $0.0036(8.33 \%)$ \\
Mean Load & - & $0.0063(25 \%)$ & - \\
\hline
\end{tabular}

TABLE V Mean, incidence (\%) and range (ppm) of organochlorine pesticides in cheese brand no. 5

\begin{tabular}{lccc}
\hline & 1993 & 1994 & $\begin{array}{c}\text { Total } \\
(1993,1994)\end{array}$ \\
\hline Lindane & $0.0088(87.5 \%)$ & $0.0339(87.5 \%)$ & $0.0213(87.5 \%)$ \\
& $0.0018-0.0275$ & $0.0154-0460$ & $0.0018-0.0460$ \\
Heptachlor & $0.0120(100 \%)$ & $0.0092(37.5 \%)$ & $0.0112(68.75 \%)$ \\
epoxide & $0.0021-0.0395$ & $0.0077-0.0115$ & $0.0021-0.0395$ \\
DDE & $0.0018(12.5 \%)$ & $0.0180(62.5 \%)$ & $0.0153(37.5 \%)$ \\
& - & $0.0082-0.0314$ & $0.0018-0.0314$ \\
o,p'-TDE & - & $0.0048(62.5 \%)$ & $0.0048(31.25 \%)$ \\
p,p'-TDE & - & $0.0009-0.0141$ & $0.0009-0.0141$ \\
& - & $0.0222(12.5 \%)$ & $0.0222(6.25 \%)$ \\
DDT & - & - & - \\
& & $0.3995(62.5 \%)$ & $0.3995(31.25 \%)$ \\
Dieldrin & - & $0.0579-0.8581$ & $0.0579-0.8581$ \\
& 0.0216 & $0.0013(12.5 \%)$ & $0.0013(6.25 \%)$ \\
Mean Load & & - & - \\
\hline
\end{tabular}


TABLE VI Mean, incidence (\%) and range (ppm) of organochlorine pesticides in cheese brand no. 6

\begin{tabular}{llll}
\hline & 1993 & \multicolumn{1}{c}{1994} & \multicolumn{1}{c}{$\begin{array}{c}\text { Total } \\
(1993,1994)\end{array}$} \\
\hline Lindane & $0.0073(37.5 \%)$ & $0.0253(87.5 \%)$ & $0.0199(62.5 \%)$ \\
& $0.0050-0.0102$ & $0.0156-0.0537$ & $0.0050-0.0537$ \\
Heptachlor & $0.0283(75 \%)$ & $0.0207(75 \%)$ & $0.0245(75 \%)$ \\
epoxide & $0.0063-0.0497$ & $0.0042-0.0782$ & $0.0042-0.0782$ \\
DDE & $0.1876(25 \%)$ & $0.0121(25 \%)$ & $0.0998(25 \%)$ \\
& $0.0261-0.3492$ & $0.0099-0.0142$ & $0.0099-0.3492$ \\
o,p'-TDE & $0.0296(12.5 \%)$ & $0.0260(37.5 \%)$ & $0.0269(25 \%)$ \\
& - & $0.0239-0.0294$ & $0.0239-0.0296$ \\
p,p'-TDE & $0.1762(25 \%)$ & $0.0262(37.5 \%)$ & $0.0862(31.25 \%)$ \\
& $0.0056-0.3467$ & $0.0042-0.0411$ & $0.0042-0.3467$ \\
DDT & $0.9048(12.5 \%)$ & $0.2131(25 \%)$ & $0.4437(18.75 \%)$ \\
& - & $0.1762-0.2501$ & $0.1762-0.9048$ \\
Aldrin & $0.0055(12.5 \%)$ & $0.0113(50 \%)$ & $0.0101(31.25 \%)$ \\
& - & $0.0064-0.0187$ & $0.0055-0.0187$ \\
Dieldrin & $0.0046(25 \%)$ & $0.0063(50 \%)$ & $0.0057(37.5 \%)$ \\
Mean Load & $0.0032-0.0059$ & $0.0026-0.0100$ & $0.0026-0.0100$ \\
\hline
\end{tabular}

heptachlor (incl. epoxide). These values are similar to those proposed by the Codex Committee on Pesticide Residues FAO/WHO in milk (mg/kg on fat basis): 0.25 for lindane, 0.15 for heptachlor (incl. epoxide), 0.15 for aldrin (incl. dieldrin), and 1.25 for DDT (incl. metabolites).

In any case the maximum residue limits established by the organisms above mentioned were exceeded by the detected concentrations in cheese samples analyzed in this study. The comparison of the results obtained with the maximum levels allowed by EU for cheese samples can be seen in Figure 2 .

We have not found any references reporting organochlorine residue levels in cheese. Losada et al. [3] have published in 1996 a paper studying organochlorine residues in milk samples. The samples had been collected in 1992 in several farms located in the southern area of the province of León, near the factories where cheese brands no. 4,5 and 6 were manufactured. In the study, lindane was the most detected pesticide (66.7\%) and the highest mean residue level was for $\mathrm{p}, \mathrm{p}^{\prime}$-DDE $(0.005 \mathrm{ppm} /$ wet weight). Heptachlor epoxide was only found in $20.5 \%$ of the samples and DDT and related compounds in $23 \%$.

Hernández et al. [11] carried out a study in human breast milk collected in Madrid. These authors found $100 \%$ incidence percentage for DDT and

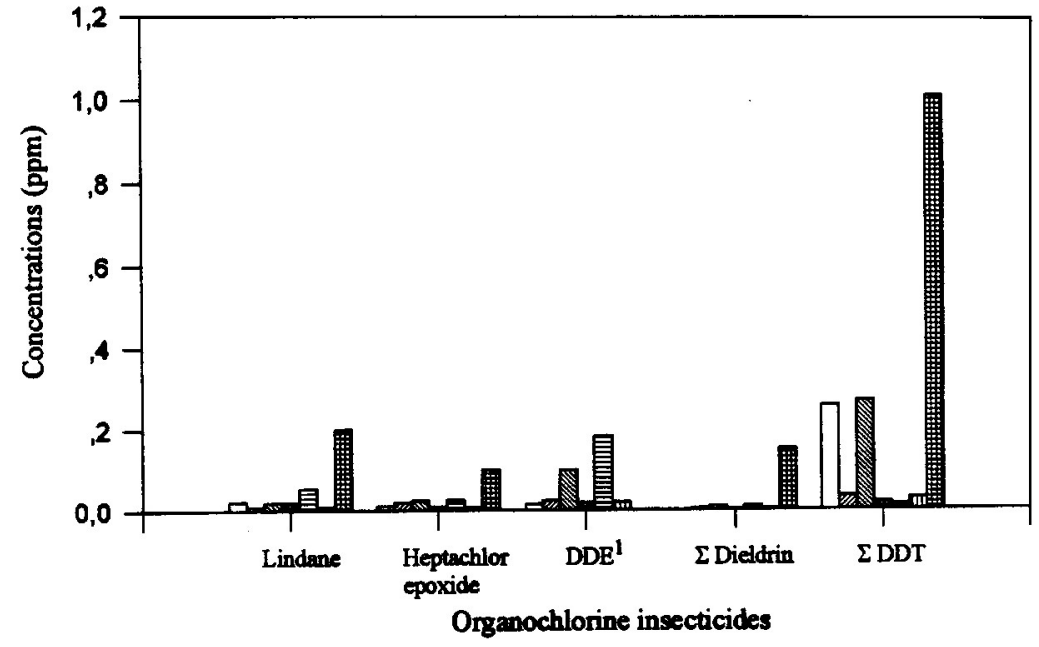

FIGURE 2 Mean levels (in ppm/fat basis) of organochlorine pesticides in the six cheese brands:

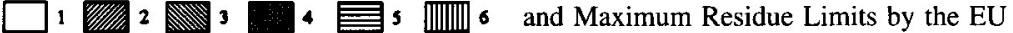

${ }^{1}$ Not established value.

related compounds and $68.6 \%$ for lindane. The lindane incidence percentage in this study was very similar $(62.0 \%)$ but the incidence for DDT and related compounds was lower $(59.9 \%)$.

In order to evaluate the influence of the cheese brand and date of sampling on the total load, a two-way analysis of variance (ANOVA) was used. No significant differences were found in relation to sampling period (spring, summer, autumn, winter), but the total load showed significant differences between the brand no. $6(\bar{x}=0.2034 \mathrm{ppm})$ and the brands no. $2(\bar{x}=$ $0.0353 \mathrm{ppm})$, no. $3(\bar{x}=0.0482 \mathrm{ppm})$ and no. $4(\bar{x}=0.0538 \mathrm{ppm})$. When samples were grouped according to the year of sampling $(1993,1994)$ the oneway ANOVA analysis indicated that there were only significant differences in the total load for cheese samples in brand no. $5(\bar{x}=0.0216 \mathrm{ppm}$ in 1993 and $\bar{x}=0.3000 \mathrm{ppm}$ in 1994). In 1993 significant differences were found between the total load of cheese no. 6 and all the others, but in 1994 there were no significant differences.

Finally, in order to evaluate the influence of geographical area on the total load the samples were grouped taking into account the location of the factories: samples from north area (brands no. 1,2, and 3) and from south area (brands no. 4, 5, and 6). The ANOVA analysis indicated that there were no significant differences between different periods of sampling but it showed significant differences in pesticide load between the two geographical areas. 


\section{References}

[1] K. Kannan, S. Tanabe, A. Ramesh, A. Subramanian and R. Tatsukawa (1992). Persistent organochlorine residues in foodstuffs from India and their implications on human dietary exposure. J. Agric. Food Chem., 40, 518-524.

[2] M. Horn, B. Heinzow and G. Dolk. (1994). Contamination of human milk with DDT, HCH, $\mathrm{HCB}$, and PCB on the territory of the former GDR. Investigation and residue interpretation. Zbl. Hyg., 196, 95-103.

[3] A. Losada, N. Fernández, M. J. Diez, M. T. Terán, J. J. García and M. Sierra (1996). Organochlorine pesticide residues in bovine milk from León (Spain). Sci. Tot. Environ., 181, $133-135$.

[4] European Union (1992). Diario Oficial de las Comunidades Europeas, L 251, de 23 de julio de 1992.

[5] Ministerio de Sanidad y Consumo (1994). Orden de 4 de febrero de 1994, BOE número 477 de 17 de febrero de 1994.

[6] European Union (1993). Diario Oficial de las Comunidades Europeas, L 211, de 23 de agosto de 1993.

[7] Codex Alimentarius Commission, "Guide to Codex Recommendations Concerning Pesticide Residues", CAC/PR Guide, FAO/WHO, Rome (1986).

[8] L. D. Sawyer, B. M. McMahon, W. H. Newsome and G. A. Parker (1990). (Eds.). Pesticide and industrial chemical residues. In: K. Helrich (Ed.), Official Methods of Analysis. $15^{\text {th }}$ Association of Official Analytical Chemists, Inc., Arlington, pp. 274-311.

[9] STATGRAPHICS plus for Windows, version 2. User Manual. Statistical Graphics Corporation, 1995.

[10] A. H. Roos and L. G. M. Th. Tuinstra (1991). Chlorinated insecticides. In: Monograph on residues and contaminants in milk and milk products. International Dairy Federation, Brussels, 84-98.

[11] L. M. Hernández, M. A. Fernández, E. Hoyas, M. J. González and J. F. García (1993). Organochlorine insecticide and polychlorinated biphenyl residues in human breast milk in Madrid (Spain). Bull. Environ. Contam. Toxicol., 50, 308-315. 